\title{
Update on the optimal use of voriconazole for invasive fungal infections
}

\author{
This article was published in the following Dove Press journal: \\ Infection and Drug Resistance \\ 2 February $201 \mathrm{I}$ \\ Number of times this article has been viewed
}

\author{
Asma Lat' \\ George R Thompson III $^{2}$ \\ 'Department of Pharmacy, \\ New York-Presbyterian Hospital, \\ Columbia University Medical Center, \\ New York, NY, USA; ${ }^{2}$ Department \\ of Medical Microbiology and \\ Immunology, Coccidioidomycosis \\ Serology Laboratory, and the \\ Department of Medicine, Division \\ of Infectious Diseases, University \\ of California-Davis, Sacramento, \\ CA, USA
}

\begin{abstract}
Voriconazole is an extended-spectrum triazole with excellent bioavailability that has now become the treatment of choice for aspergillosis. It has a unique side effect profile compared with other azoles, as well as a number of clinically important drug-drug interactions. These factors, along with a correlation between increased serum levels and improved outcomes, have prompted an interest in therapeutic drug monitoring of this agent. The pharmacology and clinical outcomes data of voriconazole are presented in this review.
\end{abstract}

Keywords: therapeutic drug monitoring, aspergillosis, candidiasis, voriconazole

\section{Introduction}

Invasive fungal infections (IFIs) are responsible for significant morbidity and mortality. Mortality from invasive candidiasis has decreased in recent years, but diseases due to other fungi, including Aspergillus spp., have led to an overall increase in deaths from IFIs. ${ }^{1-4}$ The number of immunocompromised patients at risk for IFIs has also increased during this same time period as more patients are exposed to immunosuppressants and intense chemotherapy regimens. ${ }^{5}$ Amphotericin B deoxycholate has traditionally been the foundation of treatment for IFIs since its approval by the US Food and Drug Administration (FDA) in the 1950s. However, several new broadspectrum antifungals, including voriconazole, have become available during the past 15 years in an effort to improve treatment outcomes and minimize drug toxicities in the growing at-risk population. Voriconazole, a widely utilized mold-active triazole, is the subject of this review.

\section{Pharmacology Azole antifungals}

Ketoconazole, an imidazole antifungal, was the first systemic azole approved by the FDA in 1979. Use of the imidazoles has since been restricted to topical treatment of superficial fungal infections due to the lack of enzyme specificity and ensuing adverse effects with systemic therapy. Alteration of ketoconazole's structure resulted in the development of the initial triazole, fluconazole. Fluconazole was considered an advancement over previous azole antifungals due to its enhanced safety and efficacy, but its spectrum of activity lacked coverage against clinically important molds, including Aspergillus spp. Fluconazole was followed chronologically by the introduction of itraconazole, which added activity against Aspergillus. The clinical use of itraconazole, however, is limited by its low oral bioavailability and side effect profile. The expanded-spectrum triazoles
Correspondence: George R Thompson III University of California-Davis,

Coccidioidomycosis Serology Laboratory, One Shields Avenue, Rm 3134, Davis, CA 95616, USA

Tel $+|530752| 757$

Fax +I 5307528692

Email grthompson@ucdavis.edu 
voriconazole and posaconazole were then formulated to provide potent activity against a variety of yeasts and molds while reducing treatment-limiting adverse effects. ${ }^{6}$ These agents have subsequently become the preferred agents for the treatment and prophylaxis of invasive aspergillosis, respectively. ${ }^{7}$ This review will highlight the in vitro activity and mechanisms of resistance, pharmacokinetics/ pharmacodynamics, rationale for therapeutic drug monitoring (TDM), clinical efficacy, adverse effects, and drug interactions associated with voriconazole.

\section{Mechanism of action}

The azoles enact their antifungal effects within the fungal cell membrane by blocking the P450 (CYP)-dependent demethylation of lanosterol, leading to the inhibition of ergosterol synthesis (Figure 1). This process causes toxic methylsterols to accumulate in the fungal cell membrane and prevents fungal cell growth and replication. Differences between azoles in antifungal potency and activity are attributed to differences in their affinity for the 14- $\alpha$-demethylase enzyme. The toxicity and drug interaction profiles of the azoles, including voriconazole, are due to cross-inhibition of various human CYP-dependent enzymes. Voriconazole, like other triazoles, is fungistatic against most yeasts but has fungicidal activity against molds, including Aspergillus. ${ }^{8-10}$

In addition to the antifungal activity described previously, the triazoles also possess immunomodulatory effects that have only recently been identified and are still being elucidated. These indirect antifungal effects are likely to gain more relevance in clinical practice as IFIs disproportionately affect patients with immunodeficiencies. In vitro models have shown that ergosterol depletion enhances fungal cell susceptibility to both oxidative and nonoxidative phagocytic damage. ${ }^{11}$ Voriconazole also specifically induces the expression of toll-like receptor 2, nuclear factor- $\kappa \mathrm{B}$, and tumor necrosis factor alpha in monocytes. ${ }^{12}$

\section{In vitro activity and mechanisms of resistance}

Voriconazole, like other extended-spectrum triazoles, is active against a wide variety of invasive mycoses, including Candida, Cryptococcus, most dimorphic fungi, Aspergillus, and other yeasts and hyaline molds (Table 1). Voriconazole is not active against Sporothrix schenckii and members of the Zygomycetes group, however. Cross-resistance against Candida spp. is common, and only about $30 \%$ of fluconazole-resistant C. albicans, C. glabrata, C. tropicalis, and C. rugosa isolates remain susceptible to voriconazole; thus, fluconazole is often used as a surrogate marker of voriconazole resistance. ${ }^{13,14}$ Therefore, susceptibility testing is recommended prior to usage of voriconazole for candidiasis secondary to fluconazole-resistant strains. The European Committee on Antimicrobial Susceptibility Testing (EUCAST) defines minimum inhibitory concentrations (MICs) $\leq 0.125 \mu \mathrm{g} /$

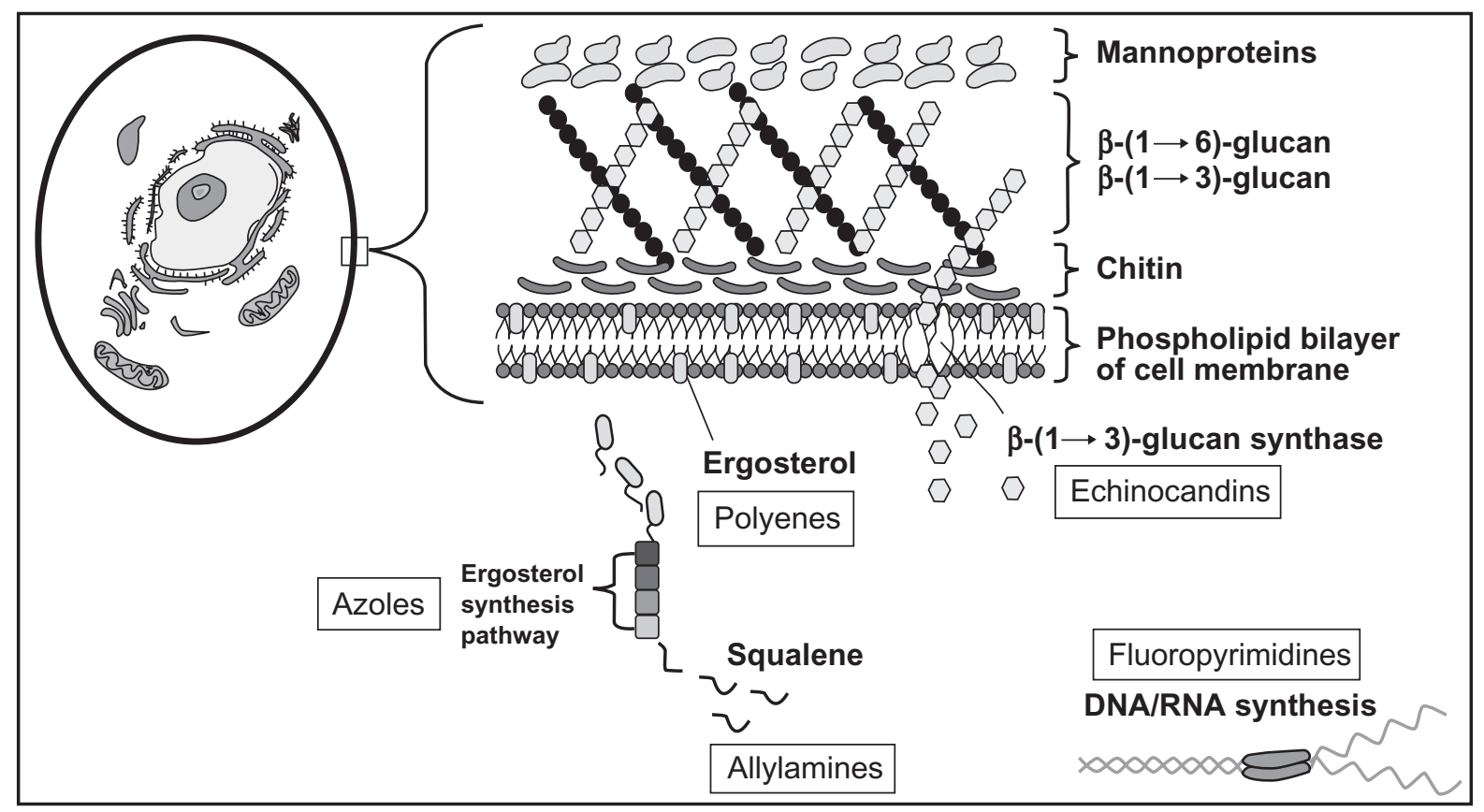

Figure I Targets of systemic antifungal agents.

Reproduced with permission from reference 6. 
Table I Voriconazole spectrum of activity

\begin{tabular}{lc}
\hline Organism & Activity \\
\hline Aspergillus species & + \\
Candida species $^{\mathrm{a}}$ & + \\
Cryptococcus neoformans $^{\text {Coccidioides species }}$ & + \\
Blastomyces & + \\
Histoplasma species & + \\
Fusarium species & + \\
Scedospermium apiospermum & + \\
Scedosporium prolificans & + \\
Sporothrix schenckii & \pm \\
Zygomycetes & - \\
\hline
\end{tabular}

Notes: Plus (+) signs indicate activity against the listed organism. Minus (-) signs indicate a lack of activity against the listed organism. Plus-minus signs $( \pm)$ indicate variable activity against the listed organism. ${ }^{a}$ Cross-resistance with fluconazole common. Modified from reference 6 .

$\mathrm{mL}$ as susceptible for C. albicans, C. parapsilosis, and C. tropicalis, whereas the Clinical and Laboratory Standards Institute (CLSI) does not differentiate between Candida spp. and defines MICs $\leq 1 \mu \mathrm{g} / \mathrm{mL}$ as being susceptible. ${ }^{15,16}$

Mutations within the ERG11 gene (CgERG11), which encodes the azole target enzyme, and upregulation of the CgCDR1 and CgCDR2 genes, which encode drug efflux pumps, lead to voriconazole resistance in C. glabrata ${ }^{17}$ Similar mechanisms have also been identified in other voriconazole-resistant Candida spp. Unlike other Candida spp., the majority of $C$. krusei isolates remain susceptible to voriconazole, despite inherent fluconazole resistance, likely due to more avid binding to the $14 \alpha$-demethylase target enzyme. ${ }^{18,19}$

Resistance to mold-active triazoles among Aspergillus spp. is still considered to be an uncommon occurrence, though specific rates are not completely known, as few centers actively monitor for resistance. Alteration of the $14 \alpha$-sterol demethylase enzyme encoded by the CYP51A and CYP51B genes appears to be the most commonly described mechanism of resistance to this class. An amino acid substitution at position M220 confers panazole resistance, and a substitution at position G54 leads only to itraconazole and posaconazole resistance. ${ }^{20,21}$ Several other novel amino acid modifications have also recently been described. ${ }^{22,23}$ Conflicting reports exist regarding the exact incidence of resistance to voriconazole in Aspergillus spp. A recent survey detected voriconazole MICs $>2 \mu \mathrm{g} / \mathrm{mL}$ in less than $1 \%$ of 771 clinical Aspergillus spp. isolates, whereas other researchers have noted increasing resistance during the last 5 years. ${ }^{24-26}$ Notably, emerging mechanisms of resistance yet to be fully characterized may be responsible for the recent increase in voriconazole-resistant Aspergillus in some geographic locales. ${ }^{26}$ Given the evolving nature of resistance in the face of increasing use of broad-spectrum azoles, it seems prudent to maintain vigilance in surveillance activities.

\section{Pharmacokinetics and pharmacodynamics}

Voriconazole, unlike other broad-spectrum triazoles, is available in both oral and intravenous dosage forms. The intravenous formulation is solubilized in sulfobutyl ether $\beta$-cyclodextrin (SBECD). ${ }^{27}$ Steady-state levels are attained after $5-6$ days when $3-6 \mathrm{mg} / \mathrm{kg} /$ day of voriconazole is administered. However, intravenous loading doses reduce the time to reach steady state to only 1 day. ${ }^{28}$ Similarly, oral loading doses also lead to achievement of steady-state levels within 24 hours. Oral bioavailability is $>90 \%$ when doses are administered 1 hour prior to or after a meal. ${ }^{29}$ Absorption is not reliant on gastric acidity, but fatty foods reduce bioavailability by approximately $20 \% .^{30}$ Voriconazole has a large volume of distribution $(4 \mathrm{~L} / \mathrm{kg}$ ) and is approximately $60 \%$ protein bound. Tissue levels may exceed serum levels, and cerebrospinal fluid (CSF) levels, which are lower than brain levels, are usually about $50 \%$ concomitant serum values. ${ }^{31}$ Less than $2 \%$ of active drug is excreted renally.

Voriconazole has linear pharmacokinetics in children but exhibits nonlinear pharmacokinetics in adults, which can lead to complicated dosing scenarios. The nonlinear kinetics seen in adults are likely due to saturable metabolism. ${ }^{28}$ Voriconazole is hepatically metabolized via the CYP450 system through the CYP2C9, CYP2C19, and CYP3A4 isoenzymes. Not surprisingly, these isoenzymes are also responsible for the majority of drug-drug interactions associated with voriconazole (see Drug-drug interactions).

Like other triazoles, area under the curve (AUC)/MIC is the pharmacodynamic parameter that best describes voriconazole's antifungal efficacy. Nonlinear pharmacokinetics and high interpatient variability, however, complicate the evaluation of concentration-effect relationships in humans (see Therapeutic drug monitoring). ${ }^{27}$

\section{Dosing}

As mentioned previously, loading doses are recommended for both the oral and intravenous formulations. In patients aged $\geq 12$ years, intravenous dosing consists of $6 \mathrm{mg} / \mathrm{kg}$ twice daily on day 1 followed by $4 \mathrm{mg} / \mathrm{kg}$ twice daily for the remainder of treatment. Oral dosing in adults is weight based. Per the package insert, adult patients weighing $>40 \mathrm{~kg}$ should receive $400 \mathrm{mg}$ twice daily on day 1 followed by $200 \mathrm{mg}$ twice daily until the end of therapy, whereas a $200 \mathrm{mg}$ 
twice-daily loading dose on day 1 followed by $100 \mathrm{mg}$ twice daily, is recommended for those weighing $<40 \mathrm{~kg}$. ${ }^{27}$ However, many clinicians opt to approximate oral dosing to intravenous dosing by administering the loading $(6 \mathrm{mg} / \mathrm{kg})$ and maintenance $(4 \mathrm{mg} / \mathrm{kg}$ ) doses rounded up to the nearest pill size (oral formulation available as $200 \mathrm{mg}$ and $50 \mathrm{mg}$ tablets). ${ }^{7}$ Pediatric dosing reflects the rapid metabolism and linear kinetics seen in this population and is recommended at $7 \mathrm{mg} / \mathrm{kg}$ twice daily intravenously and $200 \mathrm{mg}$ orally twice daily, both without loading doses.

Dose adjustments are required for patients with mild to moderate hepatic dysfunction (Child-Pugh Class A and B). The standard loading dose should be provided to these patients, but maintenance doses should be reduced by $50 \%{ }^{32}$ Studies have not adequately evaluated the safety of voriconazole in severe liver disease (Child-Pugh Class C). Dosage adjustment is not required in patients with renal insufficiency if oral voriconazole is administered, but the SBECD vehicle present in the intravenous formulation may accumulate in these patients. For this reason, intravenous voriconazole should be avoided when creatinine clearance is $<50 \mathrm{~mL} / \mathrm{min}$ unless the potential benefit outweighs the risk. ${ }^{27}$

Like other triazoles, voriconazole is teratogenic in animals and should be avoided during pregnancy and while the mother is breastfeeding. ${ }^{33}$

\section{Therapeutic drug monitoring}

Voriconazole has a number of complex pharmacokinetic properties that make TDM an integral component of optimizing antifungal therapy with this agent. A large degree of pharmacokinetic variability at standard doses, both inter- and intrapatient, is an important characteristic that necessitates TDM of voriconazole. ${ }^{34}$ Additionally, a large number of drug-drug interactions complicate treatment with voriconazole by influencing its pharmacokinetics or the pharmacokinetics of other drugs that are given simultaneously. ${ }^{35}$

The pharmacokinetic variability seen with voriconazole is likely multifactorial. First, the activity of the primary metabolic enzyme CYP2C19 P450 differs significantly between ethnic groups. ${ }^{36}$ Genetic polymorphisms of the CYP2C19 enzyme result in patients who are homozygous extensive metabolizers, heterozygous extensive metabolizers, or homozygous poor metabolizers. Patients of Asian ethnicity are likely to be homozygous poor metabolizers, which predisposes them to higher voriconazole serum levels. This is in stark contrast with Caucasians, about $75 \%$ of whom are homozygous extensive metabolizers and thus have lower voriconazole concentrations. A commercial CYP2C19 genotype testing product has recently become available (Genelex, Seattle, WA, USA), but it is unclear whether use of this assay will gain widespread use and how clinicians will use results from the test to adjust empiric dosing regimens.

Voriconazole is known to interact with numerous medications that are likely to be used in patients at high risk for IFIs, including tacrolimus, cyclosporine, and sirolimus. These drugs all undergo significant changes in their pharmacokinetics when coadministered with voriconazole. ${ }^{6}$ Additionally, several drugs that are often used in patients with HIV, such as rifamycins, phenytoin, long-acting barbiturates, and carbamazepine, markedly decrease voriconazole levels and may lead to clinical failure when given concurrently with voriconazole. ${ }^{6}$ It has recently been reported that autoinduction of voriconazole metabolism at higher doses is possible and that voriconazole trough levels seem to decrease over time without any apparent explanation. ${ }^{37,38}$ All of these identified issues may considerably alter voriconazole pharmacokinetics and thus make TDM an attractive means of monitoring treatment.

In addition to the aforementioned pharmacokinetic issues that support the use of TDM, clinical outcomes data exist that cohesively associate low voriconazole serum levels with poor outcomes and thus further strengthen the argument for TDM. Denning et al were the first group to report this correlation. ${ }^{39}$ They found high failure rates (60\%) in patients with invasive aspergillosis and random voriconazole levels $\leq 0.25 \mu \mathrm{g} / \mathrm{mL}$. Smith et al subsequently studied 17 patients clinically failing voriconazole treatment (mostly for invasive aspergillosis) and had serum concentrations taken. ${ }^{40}$ All 17 patients had levels $<2.51 \mu \mathrm{g} / \mathrm{mL}$, which the authors noted is below the median value seen in clinical trials of voriconazole. Interestingly, weight did not seem to affect voriconazole serum concentrations, which is consistent with the FDA briefing document on voriconazole. ${ }^{35}$ Voriconazole levels $<2 \mu \mathrm{g} / \mathrm{mL}$ led to dose increases in 11 patients, and 8 of these 11 patients survived their infections. Another important finding from this study was that all patients with a voriconazole level $>2.05 \mu \mathrm{g} / \mathrm{mL}$ survived, whereas only 8 of 18 patients with a level $<2.05 \mu \mathrm{g} / \mathrm{mL}$ lived $(P<0.025)$. This study provided important information regarding the relationship between voriconazole serum concentrations and clinical outcomes but is limited by the low number of patients and a lack of a clear definition of when levels were taken.

Pascual et al conducted the most important study to date examining the relationship between voriconazole serum levels and clinical outcomes. ${ }^{41}$ The authors obtained 181 voriconazole serum concentrations from a total of 52 patients, and targeted 
trough levels between $1 \mu \mathrm{g} / \mathrm{mL}$ and $5.5 \mu \mathrm{g} / \mathrm{mL}$. They chose this range because the $\mathrm{MIC}_{90}$ for most organisms targeted by voriconazole is between $0.5 \mu \mathrm{g} / \mathrm{mL}$ and $1 \mu \mathrm{g} / \mathrm{mL}$, and toxicities generally occur at serum levels $>5.5 \mu \mathrm{g} / \mathrm{mL}$. An important distinction between this study and the previously mentioned studies is that the authors provide recommendations for voriconazole dose changes based on trough levels obtained. This study also provided several important results that should be taken into consideration when managing specific patients in clinical practice. First, the authors found substantial intradose variability between serum levels from individual patients. Second, though the authors state that there was no significant difference in trough levels between the different daily dosages ranging from $\leq 5 \mathrm{mg} / \mathrm{kg} /$ day to $\geq 8 \mathrm{mg} / \mathrm{kg} /$ day, the mean trough concentration appeared to be substantially higher in the $\geq 8 \mathrm{mg} / \mathrm{kg} /$ day group than in the others (2.9 vs 1.7 vs 1.2 vs 1.7 ). Trifilio et al also failed to find a significant correlation between dose and voriconazole trough levels. ${ }^{42}$

Pascual et al found that patients with voriconazole serum levels $<1.0 \mu \mathrm{g} / \mathrm{mL}$ had significantly lower response rates than those patients with levels $>1.0 \mu \mathrm{g} / \mathrm{mL}$ (46\% vs $12 \% ; P=0.02$ ), and patients with levels $<1.0 \mu \mathrm{g} / \mathrm{mL}$ were more likely to be receiving oral therapy. ${ }^{41}$ The median daily oral voriconazole dose was $6 \mathrm{mg} / \mathrm{kg}$, and patients receiving intravenous treatment had a median dose of $7.5 \mathrm{mg} / \mathrm{kg} /$ day. This raises an important point regarding dosing of voriconazole, as the package insert for voriconazole indicates weight-based dosing for the intravenous formulation but recommends a fixed dose for the oral formulation. Thus, when patients are transitioned from intravenous to oral voriconazole, it is possible for substantial dose reductions to occur, potentially placing them at risk for therapeutic failure. Of note, all six patients whose infections progressed while receiving voriconazole regimens that led to levels of $<1.0 \mu \mathrm{g} / \mathrm{mL}$ exhibited clinical improvement once their doses were increased to achieve serum troughs $>1.0 \mu \mathrm{g} / \mathrm{mL}$. Additional statistical analysis predicted a $70 \%$ success rate with voriconazole troughs $>1.0 \mu \mathrm{g} / \mathrm{mL}$.

Although low serum voriconazole levels predict poor clinical outcomes, adverse effects due to voriconazole have been associated with increased voriconazole concentrations. The FDA briefing document for voriconazole indicates that a significant correlation exists between increased voriconazole maximum concentration $\left(\mathrm{C}_{\max }\right)$ and $\mathrm{AUC}$ and elevated transaminases and thus recommends that serum voriconazole levels should not surpass $5.0 \mu \mathrm{g} / \mathrm{mL} .{ }^{35}$ Abnormalities in liver function tests are a well-known adverse effect of azoles and were the primary toxicity associated with voriconazole until recently. Central nervous system (CNS) adverse effects, including hallucinations, are increasingly being reported in the literature. The study by Pascual et al noted that five (31\%) patients with voriconazole serum levels $>5.5 \mu \mathrm{g} / \mathrm{mL}$ experienced hallucinations, but no patients with serum concentrations $<5.5 \mu \mathrm{g} / \mathrm{mL}$ reported similar toxicities. ${ }^{41}$ A separate study by Zonios et al also described similar occurrences in 12 of 72 patients. ${ }^{43}$ Eight of the 12 patients reported hallucinations with the initial loading doses of intravenous voriconazole, and five of six patients with serum voriconazole trough concentrations had levels $>5.2 \mu \mathrm{g} / \mathrm{mL}$. These data provide further evidence that elevated serum voriconazole trough concentrations are correlated not only with hepatoxicity but also with CNS adverse effects.

Despite evidence that TDM may be a necessary component of managing voriconazole therapy due to unpredictable pharmacokinetics and the correlation with clinical outcomes and toxicities, many clinicians do not routinely employ TDM. This underutilization of TDM may be due to the delay in obtaining results in a timely manner, as few laboratories perform the assay. As more data accumulate in this research area, it is possible that voriconazole TDM will become the standard of care as a means to optimize therapy with this important antifungal.

\section{Safety and tolerability}

Voriconazole is typically well tolerated, and the side effect profile is similar to that of other triazoles but with a few notable differences (Table 2). In a study that compared voriconazole with fluconazole for esophageal candidiasis, patients receiving voriconazole experienced more treatment-related side

Table 2 Adverse effects of voriconazole

\begin{tabular}{|c|c|}
\hline Organ system & Adverse effect \\
\hline \multirow[t]{2}{*}{ Special senses } & Altered light perception \\
\hline & Photophobia, blurred vision $(<30 \%)$ \\
\hline Cardiovascular system & QTc prolongation \\
\hline \multirow[t]{2}{*}{ Gastrointestinal disorders } & Nausea, vomiting $(<5 \%)$ \\
\hline & Abdominal pain $(<10 \%)$ \\
\hline Endocrine system & Adrenal insufficiency (rare) \\
\hline \multirow[t]{2}{*}{ Liver and biliary system } & Increased transaminases $(<15 \%)$ \\
\hline & Hepatitis (rare) \\
\hline \multirow[t]{2}{*}{ Central nervous system } & Hallucinations, confusion (10\%) \\
\hline & Headache \\
\hline \multirow[t]{2}{*}{ Skin and appendages } & Pruritis, rash $(<10 \%)$ \\
\hline & Photosensitivity (<2\%) \\
\hline Immunologic & Anaphylaxis reported \\
\hline $\begin{array}{l}\text { Maximum tolerated dose in } \\
\text { clinical trials }\end{array}$ & 800 mg/day (10 mg/kg/day) \\
\hline
\end{tabular}


effects than those who received fluconazole (30\% vs 14\%). Gastrointestinal side effects were frequently encountered and were similar between the two drugs $(9 \%)$, but the most common toxicity due to voriconazole was transient, infusionrelated abnormal vision that was not sight threatening (23\%). Visual effects may manifest as altered color discrimination, blurred vision, appearance of wavy lines and bright spots, and photophobia. This distinctive adverse effect usually occurs 30 minutes after infusion, subsides 30 minutes later, is not known to cause long-term retinal sequelae, and tends to dissipate after the first week of treatment. ${ }^{27}$ Infusion-related side effects were also the most common voriconazole-related adverse reactions in a large, randomized, multicenter trial that compared intravenous voriconazole with liposomal amphotericin B for empiric antifungal therapy in febrile neutropenia. ${ }^{44}$ Nearly $25 \%$ of patients reported photopsia in this study, but discontinuation of voriconazole due to treatment-related side effects was uncommon.

More familiar side effects of voriconazole treatment include skin rash and transaminase elevation. ${ }^{39}$ Most rashes are mild, but severe reactions, including Stevens-Johnson syndrome and toxic epidermal necrolysis, have been observed in a few patients. Patients should be warned to avoid direct sunlight, because photosensitivity reactions are possible. Recently, several reports have described a possible association between long-term voriconazole use and skin cancer, including aggressive squamous cell carcinoma and melanoma, in the setting of severe photosensitivity reactions. ${ }^{45-49}$ Surveillance for skin cancer formation in patients requiring long-term voriconazole therapy, particularly those who exhibit photosensitivity or chronic photodamage, is now recommended. Monitoring of LFTs is recommended at baseline, within the first 2 weeks of treatment initiation, and periodically thereafter; fulminant hepatic failure has been rarely reported. ${ }^{50}$ Similar to other triazoles, QTc prolongation has been attributed to voriconazole, and concurrent QTc-prolonging agents should be avoided if possible. ${ }^{51}$ As described previously (see Therapeutic drug monitoring), serum trough concentrations $>5.5 \mu \mathrm{g} / \mathrm{mL}$ have been correlated with CNS toxicities unique to voriconazole compared with other triazoles. ${ }^{41,43}$

Animal studies indicate that accumulation of SBECD (the solubilizing agent used in the intravenous voriconazole formulation) can result in hepatic and renal toxicities as a result of massive cytoplasmic vacuolation. ${ }^{27}$ The minimal lethal dose in animal experiments was $2000 \mathrm{mg} / \mathrm{kg}$, however, and acute toxicities were uncommon. Available clinical data in humans with impaired renal function and those undergoing renal replacement therapies also indicate an accumulation of SBECD during treatment with intravenous voriconazole, but toxic effects have not been observed. ${ }^{52-54}$ Larger, prospective studies are needed to fully evaluate the effects of intravenous voriconazole in patients with renal dysfunction.

\section{Drug-drug interactions}

Treatment with voriconazole is often complicated by the potential for myriad drug-drug interactions due to its metabolism by and inhibition of CYP450 2C19, 3A4, and 2C9 enzymes (Tables 3 and 4). ${ }^{55-64}$ Inhibition of CYP3A4 can lead to a significant increase in serum levels of cyclosporine, tacrolimus, warfarin, methadone, statins, benzodiazepines, diltiazem, vinca alkaloids, sulfonylureas, omeprazole, phenytoin, protease inhibitors, and nonnucleoside reverse transcriptase inhibitors. Dose adjustments are required for most of these agents, as well as monitoring of serum levels and/or markers of their activity and toxicity. When voriconazole is discontinued, care must be taken to increase doses of these drugs as well. Potent CYP3A4 inducers, such as rifampin, carbamazepine, and long-acting barbiturates, can lead to decreased voriconazole serum concentrations and should be avoided in combination with voriconazole. Additionally, complex two-way drug interactions are also possible with voriconazole when used concomitantly with efavirenz, phenytoin, and rifabutin. ${ }^{58,60}$ These drugs all lead to an appreciable reduction in voriconazole levels, whereas voriconazole considerably increases their concentrations. Numerous drugs are contraindicated for use with voriconazole, including sirolimus, quinidine, ergot alkaloids, astemizole, and cisapride, due to the risk of life-threatening adverse reactions. Despite the contraindication with sirolimus listed in the package insert, many clinicians successfully administer the two drugs simultaneously by reducing the sirolimus dose by $90 \%$ and monitoring sirolimus concentrations. ${ }^{65-67}$ Thus, voriconazole interacts with a formidable list of drugs,

Table 3 Voriconazole interactions with CYP450 enzymes

\begin{tabular}{ll}
\hline Drug mechanism & Activity \\
\hline Inhibitor & \\
$2 \mathrm{C} 19$ & +++ \\
$2 \mathrm{C} 9$ & ++ \\
$3 \mathrm{~A} 4$ & ++ \\
Substrate & \\
$2 \mathrm{C} 19$ & +++ \\
$2 \mathrm{C} 9$ & + \\
$3 \mathrm{~A} 4$ & + \\
\hline
\end{tabular}

Note: Interactions from minimal $(+)$ to extensive $(+++)$. Modified from reference 6 . 
Table 4 Summary of voriconazole-mediated drug-drug interactions

\begin{tabular}{|c|c|}
\hline Type of interaction, drug & Recommendation \\
\hline \multicolumn{2}{|l|}{ Decreases voriconazole levels } \\
\hline Carbamazepine & Contraindicated \\
\hline Long-acting barbiturates & Contraindicated \\
\hline Rifampin & Contraindicated \\
\hline Ritonavir & $\begin{array}{l}\text { Avoid unless benefit } \\
\text { outweighs risk }\end{array}$ \\
\hline \multicolumn{2}{|l|}{ Levels increased by voriconazole } \\
\hline Astemizole & Contraindicated \\
\hline Cisapride & Contraindicated \\
\hline Cyclosporine & $\begin{array}{l}\text { Reduce cyclosporine dosage by } \\
\text { half and monitor cyclosporine } \\
\text { levels }\end{array}$ \\
\hline Ergot alkaloids & Contraindicated \\
\hline Omeprazole & Reduce dosage by half \\
\hline Quinidine & Contraindicated \\
\hline Sirolimus & $\begin{array}{l}\text { Contraindicated } \\
\text { Reduce sirolimus dose by } 90 \% \\
\text { and monitor sirolimus levels }\end{array}$ \\
\hline Tacrolimus & $\begin{array}{l}\text { Reduce tacrolimus dosage by } \\
\text { two-thirds and monitor } \\
\text { tacrolimus levels }\end{array}$ \\
\hline Terfenadine & Contraindicated \\
\hline Warfarin & $\begin{array}{l}\text { Monitor prothrombin time and } \\
\text { international normalized ratio }\end{array}$ \\
\hline \multicolumn{2}{|l|}{ Decreases voriconazole levels } \\
\hline Rifabutin & Contraindicated \\
\hline Phenytoin & $\begin{array}{l}\text { Double voriconazole dosage and } \\
\text { monitor for increased phenytoin } \\
\text { levels }\end{array}$ \\
\hline Efavirenz & $\begin{array}{l}\text { Double voriconazole dosage and } \\
\text { reduce efavirenz dose by half }\end{array}$ \\
\hline $\begin{array}{l}\text { Levels likely increased by } \\
\text { voriconazole: sulfonylureas, } \\
\text { statins, vinca alkaloids, calcium } \\
\text { channel blockers, benzodiazepines }\end{array}$ & $\begin{array}{l}\text { Monitor effect of drug and } \\
\text { consider decreasing dosage } \\
\text { when voriconazole is started }\end{array}$ \\
\hline
\end{tabular}

and a careful evaluation of drug regimens is warranted prior to, during, and after voriconazole therapy to prevent serious toxicities and/or therapeutic failure.

\section{Clinical evidence}

The broad spectrum of antifungal activity of voriconazole has enabled its evaluation in a variety of clinical settings. The following sections describe the outcomes data for a number of invasive mycoses.

\section{Invasive aspergillosis}

Voriconazole has become the drug of choice for invasive aspergillosis based on the results of a large, open-label, randomized, multicenter clinical trial that compared primary treatment with voriconazole with amphotericin B deoxycholate and other licensed antifungal agents. ${ }^{7,68} \mathrm{~A}$ blinded expert review panel determined that outcomes and case definitions were well defined and thus included patients with definite or probable invasive aspergillosis. Patients were randomized to receive either intravenous voriconazole (two doses of $6 \mathrm{mg}$ per $\mathrm{kg}$ of body weight on day 1 , then $4 \mathrm{mg}$ per $\mathrm{kg}$ twice daily for at least 7 days) followed by $200 \mathrm{mg}$ orally twice daily or intravenous amphotericin B deoxycholate (1-1.5 mg per kg per day). Treating physicians were allowed to switch antifungal therapy if patients were unable to tolerate the study drug to which they were randomized; this occurred more frequently in the amphotericin B treatment arm.

A total of 277 patients were enrolled: 144 to the voriconazole arm and 133 to the amphotericin B arm. Not surprisingly, the vast majority of patients in this study $(\sim 80 \%)$ had invasive pulmonary aspergillosis and had underlying hematologic malignancies or were recipients of stem cell transplants. At week 12, significantly more patients who received voriconazole exhibited a complete or partial response compared with those patients in the amphotericin B group (53\% vs 32\%; 95\% confidence interval [CI] 10.4-32.9). Increased survival was also seen in the voriconazole group at week $12(72 \%$ vs $58 \% ; P=0.02)$. Side effects were seen less frequently with voriconazole compared with amphotericin $\mathrm{B}$ ( $13 \%$ vs $24 \% ; P=0.008)$. This landmark study proved the superiority of voriconazole over amphotericin B and thus profoundly altered the management of patients with invasive aspergillosis. Though voriconazole is considered an important advancement in the treatment of aspergillosis, outcomes are still less than optimal. Addition of an echinocandin agent to voriconazole is an attractive option to possibly improve treatment outcomes. ${ }^{69,70}$ Prospective studies of combination therapy with an echinocandin compared with voriconazole monotherapy are ongoing to determine whether clinical outcomes in this devastating disease can be improved.

\section{Candidemia}

Voriconazole has been compared with amphotericin B deoxycholate followed by fluconazole for candidemia in nonneutropenic patients in a large, multicenter, open-label study. ${ }^{71}$ Patients were randomly assigned, in a 2:1 ratio, to either voriconazole $(\mathrm{n}=283)$ or amphotericin B followed by fluconazole $(n=139)$, and the results were reviewed by an independent, blinded, data review committee. Voriconazole was noninferior to amphotericin B followed by fluconazole at 12 weeks after the end of treatment, with successful outcomes in $41 \%$ of patients in both treatment groups $(95 \%$ CI for difference $-10.6 \%-10.6 \%)$. Time to 
blood culture clearance with voriconazole was also similar to that with amphotericin B/fluconazole (median time to negative blood culture, 2.0 days), challenging the notion that a fungicidal agent is required for primary treatment of all cases of candidemia. Treatment discontinuations due to all-cause adverse events were more frequent in the voriconazole group, although most discontinuations were due to nondrug-related events, and there were significantly fewer serious adverse events and cases of renal toxicity than in the amphotericin B/fluconazole group.

The most recent Infectious Diseases Society of America (IDSA) clinical practice guidelines for invasive candidiasis assign a level AI recommendation to voriconazole for the treatment of candidemia in nonneutropenic patients. ${ }^{72}$ The authors note that voriconazole provides little benefit over fluconazole for most cases of invasive candidiasis but may be recommended for C. krusei infections or as oral stepdown therapy of susceptible $C$. glabrata.

\section{Esophageal candidiasis}

One of the earliest trials to evaluate the efficacy and safety of voriconazole was a multicenter, randomized, doubleblind, double-dummy trial versus fluconazole for esophageal candidiasis. ${ }^{73}$ This study compared voriconazole $200 \mathrm{mg}$ orally twice daily with fluconazole $200 \mathrm{mg}$ orally once daily for a minimum of 7 days after clinical resolution. There was no difference in outcomes between the two groups as determined by esophagoscopy, with success rates of $98 \%$ with voriconazole and 95\% with fluconazole. Adverse events were similar between the two agents, but visual disturbances occurred more frequently in the voriconazole group. These side effects tended to resolve during continued therapy, and no long-term adverse visual outcomes were found. Though voriconazole is as effective as fluconazole for esophageal candidiasis, it is often considered a second- to third-line agent after both fluconazole and itraconazole. ${ }^{72}$

\section{Empiric treatment during febrile neutropenia}

Empiric antifungal treatment with voriconazole during persistent neutropenic fever was evaluated in a large, openlabel, multicenter study. ${ }^{44}$ Voriconazole was compared with liposomal amphotericin B in a controversial trial where it did not meet the prespecified composite endpoint for noninferiority. Outcomes for four of the five endpoints (survival 7 days after end of therapy, discontinuation of therapy, resolution of fever, successful treatment of any baseline fungal infection) favored liposomal amphotericin B but did not reach statistical significance. However, significantly fewer breakthrough IFIs, including aspergillosis, occurred in the voriconazole arm $(2 \%$ vs $5 \% ; P=0.02)$. The FDA denied approval to voriconazole for empirical treatment of febrile neutropenia based on the failure to meet the predefined composite endpoint, but the current IDSA candidiasis guidelines provide a BI recommendation to voriconazole for the treatment of suspected invasive candidiasis in neutropenic patients. ${ }^{72}$

\section{Antifungal prophylaxis}

A recent randomized, double-blind trial sponsored by the Blood and Marrow Transplant Clinical Trials Network (BMT CTN) compared extended prophylaxis with voriconazole at $200 \mathrm{mg}$ twice daily with fluconazole $400 \mathrm{mg}$ per day after myeloablative allogeneic hematopoietic stem cell transplant (HSCT) ${ }^{74}$ Fungal-free survival rates at day 180 were similar between the two azoles ( $75 \%$ with voriconazole vs $78 \%$ with fluconazole; $P=0.49)$. There was a trend toward fewer IFIs (7\% vs $11 \% ; P=0.11)$ and aspergillosis (9 vs $17 ; P=0.09$ ) with voriconazole, as well as less frequent empiric antifungal therapy ( $24 \%$ vs $30 \% ; P=0.11)$. It should be mentioned that several centers have identified the use of voriconazole in neutropenic patients as a risk factor for subsequent pulmonary zygomycosis, and animal models suggest that voriconazole pre-exposure may increase the virulence of zygomycetes in the event of infection. ${ }^{75-77}$ Thus, although voriconazole is equivalent to fluconazole as antifungal prophylaxis for standard-risk HSCT recipients, there is insufficient evidence to promote it to a first-line prophylactic agent in this specific patient population.

\section{Cryptococcosis}

Voriconazole has potent in vitro activity against Cryptococcus neoformans and has good CSF penetration (see Pharmacokinetics and pharmacodynamics). No prospective clinical trials have been conducted with voriconazole for this infection, and only a few cases of salvage therapy have been reported..$^{78} \mathrm{~A}$ response rate of $39 \%$ was noted in 18 patients who failed, were intolerant to, or had toxicity from conventional therapy for cryptococcosis. At this time, there is little evidence to lead to a recommendation for voriconazole as a first-line agent in the treatment of invasive cryptococcosis.

\section{Endemic mycoses}

Voriconazole has demonstrated in vitro activity against the endemic fungi (Histoplasma capsulatum, Blastomyces dermatitidis, Coccidioides immitis and posadasii, Penicillium marneffi, and Paracoccidioides brasiliensis), but infections 
due to these organisms are usually treated with amphotericin B formulations, itraconazole or fluconazole. ${ }^{79-89}$ A few cases have reported efficacy with voriconazole in treating these organisms, but voriconazole cannot be routinely recommended for treatment of any endemic mycosis due to a lack of prospective trials and limited salvage data. It is notable that voriconazole does not exhibit reliable in vitro activity against Sporothrix schenckii and thus should not be considered as a treatment option for infections due to this particular endemic organism. ${ }^{81}$

\section{Hyalohyphomyces}

Voriconazole is an FDA-approved treatment for IFIs due to hyaline molds, including Fusarium, Scedosporium, and Pseudollescheria spp., based on case reports/series, as well as a lack of efficacious alternative treatment options. ${ }^{78,90}$ These fungi have become significant pathogens in severely immunosuppressed patients, particularly allogeneic stem cell transplant recipients. In vitro activity against these species is less potent than for other fungal pathogens, and susceptibility testing is warranted when considering treatment with voriconazole for infections due to these organisms.

\section{Conclusion}

Voriconazole is an extended-spectrum triazole that has now become the treatment of choice for invasive aspergillosis, fusariosis, and scedosporiosis, but it cannot be recommended over fluconazole or other antifungals for most candidal infections. Voriconazole has a unique adverse effect profile compared with other azoles, but treatment is generally well tolerated. TDM of serum levels may become more widely utilized in order to optimize treatment outcomes and minimize toxicities with voriconazole.

\section{Disclosure}

GRT has received research support from Pfizer, Merck \& Co., and Basilea. AL has no conflicts of interest.

\section{References}

1. Chamilos G, Luna M, Lewis RE, et al. Invasive fungal infections in patients with hematological malignancies in a tertiary care cancer center: an autopsy study over a 15-year period (1989-2003). Haemotologica. 2006;91:986-989.

2. Gudlaugsson O, Gillespie S, Lee K, et al. Attributable mortality of nosocomial candidemia, revisited. Clin Infect Dis. 2003;37:1172-1177.

3. Kontoyiannis DP, Marr KA, Park BJ, et al. Prospective surveillance for invasive fungal infections in hematopoietic stem cell transplant recipients, 2001-2006: overview of the Transplant-Associated Infection Surveillance Network (TRANSNET) Database. Clin Infect Dis. 2010;50: 1091-1100.
4. Pappas PG, Alexander BD, Andes DR, et al. Invasive fungal infections among organ transplant recipients: results of the Transplant-Associated Infection Surveillance Network (TRANSNET). Clin Infect Dis. 2010; 50:1101-1111.

5. Leventakos K, Lewis RE, Kontoyiannis DP. Fungal infections in leukemia patients: how do we prevent and treat them? Clin Infect Dis. 2010;50:405-415.

6. Dodds Ashley ES, Lewis R, Lewis JS, et al. Pharmacology of systemic antifungal agents. Clin Infect Dis. 2006;43:S28-S39.

7. Walsh TJ, Anaissie EJ, Denning DW, et al. Treatment of aspergillosis: clinical practice guidelines of the Infectious Diseases Society of America. Clin Infect Dis. 2008;46:327-360.

8. Espinel-Ingroff A, Boyle K, Sheehan DJ. In vitro antifungal activities of voriconazole and reference agents as determined by NCCLS methods: review of the literature. Mycopathologia. 2001;150:101-115.

9. Espinel-Ingroff A. In vitro fungicidal activities of voriconazole, itraconazole, and amphotericin B against opportunistic moniliaceous and dematiaceous fungi. J Clin Microbiol. 2001;39:954-958.

10. Clancy CJ, Nguyen MH. In vitro efficacy and fungicidal activity of voriconazole against Aspergillus and Fusarium species. Eur J Clin Microbiol Infect Dis. 1998;17:573-575.

11. Shimokawa $\mathrm{O}$, Nakayama $\mathrm{H}$. Increased sensitivity of Candida albicans cells accumulating 14 alpha-methylated sterols to active oxygen: possible relevance to in vivo efficacies of azole antifungal agents. Antimicrob Agents Chemother. 1992;36:1626-1629.

12. Ben-Ami R, Lewis RE, Kontoyiannis DP. Immunocompromised hosts: immunopharmacology of modern antifungals. Clin Infect Dis. 2008;47: 226-235.

13. Pfaller MA, Diekema DJ, Gibbs DL, et al. Results from the ARTEMIS DISK global antifungal surveillance study, 1997 to 2007: a 10.5-year analysis of susceptibilities of Candida species to fluconazole and voriconazole as determined by CLSI standardized disk diffusion. J Clin Microbiol. 2010;48:1366-1377.

14. Panackal AA, Gribskov JL, Staab JF, et al. Clinical significance of azole antifungal drug cross-resistance in Candida glabrata. J Clin Microbiol. 2006;44:1740-1743.

15. Sanguinetti M, Posteraro B, Fiori B, et al. Mechanisms of azole resistance in clinical isolates of Candida glabrata collected during a hospital survey of antifungal resistance. Antimicrob Agents Chemother. 2005;49: 668-679.

16. Pfaller MA, Diekema DJ, Gibbs DL, et al. Candida krusei, a multidrugresistant opportunistic fungal pathogen: geographic and temporal trends from the ARTEMIS DISK Antifungal Surveillance Program, 2001 to 2005. J Clin Microbiol. 2008;46:515-521.

17. Fukuoka T, Johnston DA, Winslow CA, et al. Genetic basis for differential activities of fluconazole and voriconazole against Candida krusei. Antimicrob Agents Chemother. 2003;47:1213-1219.

18. EUCAST. Clinical Breakpointsfor antifungal agents. http://www.srga. org/eucastwt/MICTAB/index.html. Accessed October 30, 2010.

19. Pfaller MA, Diekema DJ, Rex JH, et al. Correlation of MIC with outcome for Candida species tested against voriconazole: analysis and proposal for interpretive breakpoints. J Clin Microbiol. 2006;44:819-826.

20. Mann PA, Parmegiani RM, Wei SQ, et al. Mutations in Aspergillus fumigatus resulting in reduced susceptibility to posaconazole appear to be restricted to a single amino acid in the cytochrome P450 14alphademethylase. Antimicrob Agents Chemother. 2003;47:577-581.

21. Mellado E, Garcia-Effron G, Alcazar-Fuoli L, et al. Substitutions at methionine 220 in the 14alpha-sterol demethylase (Cyp51A) of Aspergillus fumigatus are responsible for resistance in vitro to azole antifungal drugs. Antimicrob Agents Chemother. 2004;48:2747-2750.

22. Howard SJ, Cerar D, Anderson MJ, et al. Frequency and evolution of azole resistance in Aspergillus fumigatus associated with treatment failure. Emerg Infect Dis. 2009;15:1068-1076.

23. Mellado E, Garcia-Effron G, Alcazar-Fuoli L, et al. A new Aspergillus fumigatus resistance mechanism conferring in vitro cross-resistance to azole antifungals involves a combination of cyp51A alterations. Antimicrob Agents Chemother. 2007;51:1897-1904. 
24. Pfaller MA, Messer SA, Boyken L, et al. In vitro survey of triazole cross-resistance among more than 700 clinical isolates of Aspergillus species. J Clin Microbiol. 2008;46:2568-2572.

25. Verweij PE, Mellado E, Melchers WJ. Multiple-triazole-resistant aspergillosis. N Engl J Med. 2007;356:1481-1483.

26. Bueid A, Howard SJ, Moore CB, et al. Azole antifungal resistance in Aspergillus fumigatus: 2008 and 2009. JAntimicrob Chemother. 2010; 65:2116-2119.

27. Johnson LB, Kauffman CA. Voriconazole: a new triazole antifungal agent. Clin Infect Dis. 2003;36:630-637.

28. Purkins L, Wood N, Ghahramani P, et al. Pharmacokinetics and safety of voriconazole following intravenous- to oral-dose escalation regimens. Antimicrob Agents Chemother. 2002;46:2546-2553.

29. Purkins L, Wood N, Kleinermans D, et al. Effect of food on the pharmacokinetics of multiple-dose oral voriconazole. $\mathrm{Br} \mathrm{J} \mathrm{Clin}$ Pharmacol. 2003;56:17-23.

30. Lazarus HM, Blumer JL, Yanovich S, Schlamm H, Romero A. Safety and pharmacokinetics of oral voriconazole in patients at risk of fungal infection: a dose escalation study. J Clin Pharmacol. 2002;42:395-402.

31. Lutsar I, Roffey S, Troke P. Voriconazole concentrations in the cerebrospinal fluid and brain tissue of guinea pigs and immunocompromised patients. Clin Infect Dis. 2003;37:728-732.

32. Weiler S, Zoller H, Graziadei I, et al. Altered pharmacokinetics of voriconazole in a patient with liver cirrhosis. Antimicrob Agents Chemother. 2007;51:3459-3460.

33. Groll AH, Gea-Banacloche JC, Glasmacher A, et al. Clinical pharmacology of antifungal compounds. Infect Dis Clin North Am. 2003;17: 159-191.

34. Theuretzbacher U, Ihle F, Derendorf H. Pharmacokinetic/ pharmacodynamic profile of voriconazole. Clin Pharmacokinet. 2006; 45:649-663.

35. Pfizer. Global Research and Development. Briefing Document for Voriconazole ftFADPAC, 1-56, 2001. http://www.fda.gov/ohrms/dockets/ ac/01/briefing/3792b2_01_Pfizer.pdf. Accessed October 31, 2010.

36. Mikus G, Schowel V, Drzewinska M, et al. Potent cytochrome P450 2C19 genotype-related interaction between voriconazole and the cytochrome P450 3A4 inhibitor ritonavir. Clin Pharmacol Ther. 2006; 80:126-135.

37. Moriyama B, Elinoff J, Danner RL, et al. Accelerated metabolism of voriconazole and its partial reversal by cimetidine. Antimicrob Agents Chemother. 2009;53:1712-1714.

38. Mulanovich V, Lewis RE, Raad, II, Kontoyiannis DP. Random plasma concentrations of voriconazole decline over time. J Infect. 2007;55: e129-e130.

39. Denning DW, Ribaud P, Milpied N, et al. Efficacy and safety of voriconazole in the treatment of acute invasive aspergillosis. Clin Infect Dis. 2002;34:563-571.

40. Smith J, Safdar N, Knasinski V, et al. Voriconazole therapeutic drug monitoring. Antimicrob Agents Chemother. 2006;50:1570-1572.

41. Pascual A, Calandra T, Bolay S, et al. Voriconazole therapeutic drug monitoring in patients with invasive mycoses improves efficacy and safety outcomes. Clin Infect Dis. 2008;46:201-211.

42. Trifilio S, Ortiz R, Pennick G, et al. Voriconazole therapeutic drug monitoring in allogeneic hematopoietic stem cell transplant recipients. Bone Marrow Transplant. 2005;35:509-513.

43. Zonios DI, Gea-Banacloche J, Childs R, Bennett JE. Hallucinations during voriconazole therapy. Clin Infect Dis. 2008;47:e7-e10.

44. Walsh TJ, Pappas P, Winston DJ, et al. Voriconazole compared with liposomal amphotericin B for empirical antifungal therapy in patients with neutropenia and persistent fever. $N$ Engl J Med. 2002;346:225-234.

45. Miller DD, Cowen EW, Nguyen JC, et al. Melanoma associated with long-term voriconazole therapy: a new manifestion of chronic photosensitivity. Arch Dermatol. 2010;146:300-304.

46. McCarthy KL, Playford EG, Looke DF, Whitby M. Severe photosensitivity causing multifocal squamous cell carcinomas secondary to prolonged voriconazole therapy. Clin Infect Dis. 2007;44:e55-e56.
47. Vanacker A, Fabre G, VanDorpe J, et al. Aggressive cutaneous squamous cell carcinoma associated with prolonged voriconazole therapy in a renal transplant patient. Am J Transplant. 2008;8: 877-880.

48. Brunel AS, Fraisse T, Lechiche C, et al. Multifocal squamous cell carcinomas in an HIV-infected patient with a long-term voriconazole therapy. AIDS. 2008;22:905-906.

49. Cowen EW, Nguyen JC, Miller DD, et al. Chronic phototoxicity and aggressive squamous cell carcinoma in children and adults during treatment with voriconazole. J Am Acad Dermatol. 2010;62:31-37.

50. Scherpbier HJ, Hilhorst MI, Kuijpers TW. Liver failure in a child receiving highly active antiretroviral therapy and voriconazole. Clin Infect Dis. 2003;37:828-830.

51. Philips JA, Marty FM, Stone RM, et al. Torsades de pointes associated with voriconazole use. Transpl Infect Dis. 2007;9:33-36.

52. Von Mach MA, Burhenne J, Weilemann LS. Accumulation of the solvent vehicle sulfobutylether beta cyclodextrin sodium in critically ill patients treated with intravenous voriconazole under renal replacement therapy. BMC Clin Pharmacol. 2006;6:6.

53. Burkhardt $\mathrm{O}$, Thon $\mathrm{S}$, Burhenne J, et al. Sulfobutylether- $\beta$-cyclodextrin accumulation in critically ill patients with acute kidney injury treated with intravenous voriconazole under extended daily dialysis. Int J Antimicrob Agents. 2010;36:93-94.

54. Alvarez-Lerma F, Allepuz-Palau A, Garcia MP, et al. Impact of intravenous of voriconazole in critically ill patients with impaired renal function. J Chemother. 2008;20:93-100.

55. Pai MP, Allen S. Voriconazole inhibition of tacrolimus metabolism. Clin Infect Dis. 2003;36:1089-1091.

56. Romero AJ, Le Pogamp P, Nilsson LG, Wood N. Effect of voriconazole on the pharmacokinetics of cyclosporine in renal transplant patients. Clin Pharmacol Ther. 2002;71:226-234.

57. Olkkola KT, Backman JT, Neuvonen PJ. Midazolam should be avoided in patients receiving the systemic antimycotics ketoconazole or itraconazole. Clin Pharmacol Ther. 1994;55:481-485.

58. Purkins L, Wood N, Ghahramani P, et al. Coadministration of voriconazole and phenytoin: pharmacokinetic interaction, safety, and toleration. Br J Clin Pharmacol. 2003;56:37-44.

59. Liu P, Foster G, Gandelman K, et al. Steady-state pharmacokinetic and safety profiles of voriconazole and ritonavir in healthy male subjects. Antimicrob Agents Chemother. 2007;51:3617-3626.

60. Liu P, Foster G, LaBadie RR, et al. Pharmacokinetic interaction between voriconazole and efavirenz at steady state in healthy male subjects. J Clin Pharmacol. 2008;48:73-84.

61. Liu P, Foster G, Labadie R, et al. Pharmacokinetic interaction between voriconazole and methadone at steady state in patients on methadone therapy. Antimicrob Agents Chemother. 2007;51:110-118.

62. Purkins L, Wood N, Kleinermans D, Nichols D. Voriconazole potentiates warfarin-induced prothrombin time prolongation. Br JClin Pharmacol. 2003;56:24-29.

63. Gerzenshtein L, Patel SM, Scarsi KK, et al. Breakthrough Candida infections in patients receiving voriconazole. Ann Pharmacother. 2005; 39:1342-1345.

64. Geist MJ, Egerer G, Burhenne J, Riedel KD, Mikus G. Induction of voriconazole metabolism by rifampin in a patient with acute myeloid leukemia: importance of interdisciplinary communication to prevent treatment errors with complex medications. Antimicrob Agents Chemother. 2007;51:3455-3456.

65. Sadaba B, Campanero MA, Quetglas EG, Azanza JR. Clinical relevance of sirolimus drug interactions in transplant patients. Transplant Proc. 2004;36:3226-3228.

66. Marty FM, Lowry CM, Cutler CS, et al. Voriconazole and sirolimus coadministration after allogeneic hematopoietic stem cell transplantation. Biol Blood Marrow Transplant. 2006;12:552-559.

67. Surowiec D, DePestel DD, Carver PL. Concurrent administration of sirolimus and voriconazole: a pilot study assessing safety and approaches to appropriate management. Pharmacotherapy. 2008;28: 719-729. 
68. Herbrecht R, Denning DW, Patterson TF, et al. Voriconazole versus amphotericin B for primary therapy of invasive aspergillosis. $N \mathrm{Engl}$ J Med. 2002;347:408-415.

69. Singh N, Limaye AP, Forrest G, et al. Combination of voriconazole and caspofungin as primary therapy for invasive aspergillosis in solid organ transplant recipients: a prospective, multicenter, observational study. Transplantation. 2006;81:320-326.

70. Marr KA, Boeckh M, Carter RA, et al. Combination antifungal therapy for invasive aspergillosis. Clin Infect Dis. 2004;39:797-802.

71. Kullberg BJ, Sobel JD, Ruhnke M, et al. Voriconazole versus a regimen of amphotericin B followed by fluconazole for candidaemia in non-neutropenic patients: a randomised non-inferiority trial. Lancet. 2005;366:1435-1442.

72. Pappas PG, Kauffman CA, Andes D, et al. Clinical practice guidelines for the management of candidiasis: 2009 update by the Infectious Diseases Society of America. Clin Infect Dis. 2009;48:503-535.

73. Ally R, Schurmann D, Kreisel W, et al. A randomized, double-blind, double-dummy, multicenter trial of voriconazole and fluconazole in the treatment of esophageal candidiasis in immunocompromised patients. Clin Infect Dis. 2001;33:1447-1454.

74. Wingard JR, Carter SL, Walsh TJ, et al. Randomized double-blind trial of fluconazole versus voriconazole for prevention of invasive fungal infection (IFI) after allo hematopoietic cell transplantation (HCT). Blood. 2010;116:5111-5118.

75. Kontoyiannis DP, Lionakis MS, Lewis RE, et al. Zygomycosis in a tertiary-care cancer center in the era of Aspergillus-active antifungal therapy: a case-control observational study of 27 recent cases. J Infect Dis. 2005; 191:1350-1360.

76. Pongas GN, Lewis RE, Samonis G, Kontoyiannis DP. Voriconazoleassociated zygomycosis: a significant consequence of evolving antifungal prophylaxis and immunosuppression practices? Clin Microbiol Infect. 2009;15:93-97.

77. Lamaris GA, Ben-Ami R, Lewis RE, et al. Increased virulence of zygomycetes organisms following exposure to voriconazole: a study involving fly and murine models of zygomycosis. J Infect Dis. 2009; 199:1399-1406.

78. Perfect JR, Marr KA, Walsh TJ, et al. Voriconazole treatment for lesscommon, emerging, or refractory fungal infections. Clin Infect Dis. 2003;36:1122-1131

79. Gonzalez GM, Fothergill AW, Sutton DA, et al. In vitro activities of new and established triazoles against opportunistic filamentous and dimorphic fungi. Med Mycol. 2005;43:281-284.
80. Li RK, Ciblak MA, Nordoff N, et al. In vitro activities of voriconazole, itraconazole, and amphotericin B against Blastomyces dermatitidis, Coccidioides immitis, and Histoplasma capsulatum. Antimicrob Agents Chemother. 2000;44:1734-1736.

81. McGinnis MR, Nordoff N, Li RK, et al. Sporothrix schenckii sensitivity to voriconazole, itraconazole and amphotericin B. Med Mycol. 2001; 39:369-371

82. Pfaller MA, Messer SA, Hollis RJ, Jones RN. Antifungal activities of posaconazole, ravuconazole, and voriconazole compared to those of itraconazole and amphotericin B against 239 clinical isolates of Aspergillus spp. and other filamentous fungi: report from SENTRY Antimicrobial Surveillance Program, 2000. Antimicrob Agents Chemother. 2002;46: 1032-1037.

83. Wheat LJ, Freifeld AG, Kleiman MB, et al. Clinical practice guidelines for the management of patients with histoplasmosis: 2007 update by the Infectious Diseases Society of America. Clin Infect Dis. 2007;45: 807-825.

84. Chapman SW, Bradsher RW Jr, Campbell GD Jr, et al. Practice guidelines for the management of patients with blastomycosis. Infectious Diseases Society of America. Clin Infect Dis. 2000;30:679-683.

85. Galgiani JN, Ampel NM, Catanzaro A, et al. Practice guideline for the treatment of coccidioidomycosis. Infectious Diseases Society of America. Clin Infect Dis. 2000;30:658-661.

86. Kauffman CA, Hajjeh R, Chapman SW. Mycoses Study Group. Practice guidelines for the management of patients with sporotrichosis. Infectious Diseases Society of America. Clin Infect Dis. 2000;30:684-687.

87. Freifeld A, Proia L, Andes D, et al. Voriconazole use for endemic fungal infections. Antimicrob Agents Chemother. 2009;53:1648-1651.

88. Supparatpinyo K, Schlamm HT. Voriconazole as therapy for systemic Penicillium marneffei infections in AIDS patients. Am JTrop Med Hyg. 2007;77:350-353.

89. Queiroz-Telles F, Goldani LZ, Schlamm HT, et al. An open-label comparative pilot study of oral voriconazole and itraconazole for longterm treatment of paracoccidioidomycosis. Clin Infect Dis. 2007;45 1462-1469.

90. Lortholary O, Obenga G, Biswas P, et al. International retrospective analysis of 73 cases of invasive fusariosis treated with voriconazole. Antimicrob Agents Chemother. 2010;54:4446-4450.

91. Voriconazole [package insert]. http://www.pfizer.com/files/products/ uspi_vfend.pdf. Accessed Novmber 5, 2010.
Infection and Drug Resistance

\section{Publish your work in this journal}

Infection and Drug Resistance is an international, peer-reviewed openaccess journal that focuses on the optimal treatment of infection (bacterial, fungal and viral) and the development and institution of preventive strategies to minimize the development and spread of resistance. The journal is specifically concerned with the epidemiology of antibiotic

\section{Dovepress}

resistance and the mechanisms of resistance development and diffusion in both hospitals and the community. The manuscript management system is completely online and includes a very quick and fair peerreview system, which is all easy to use. Visit http://www.dovepress.com/ testimonials.php to read real quotes from published authors. 